\title{
Plummer-Vinson Syndrome as an Unusual Cause of Dysphagia and Iron Deficiency Anemia in a 6-year-old Boy
}

\author{
Stefan Bittmann*, Elisabeth Luchter, Elena Moschüring-Alieva and Gloria Villalon \\ Department of Pediatrics, Ped Mind Institute, Germany
}

"Correspondence: Stefan Bittmann MD, MA, Department of Pediatrics, Ped Mind Institute, Hindenburgring 448599 Gronau, Germany, Tel: 0049-2565-97325; Fax: 0049-2565-97324; Email: stefanbittmann@ gmx.de

\begin{abstract}
We report the case of a 6-year-old boy with dysphagia and iron deficiency anemia with an $\mathrm{Hb}$ of $5.6 \mathrm{~g} / \mathrm{dl}$ leading the diagnosis of Plummer-Vinson syndrome. An esophageal stenosis of $4 \mathbf{m m}$ diameter near the upper esophageal sphincter was found. Balloon dilatation and iron substitution cured the problem. Pediatricians should keep in mind that the rare entity of Plummer-Vinson syndrome in unclear cases of dysphagia.
\end{abstract}

Keywords: Iron deficiency anemia; Plummer-vinson syndrome

Received Date: July 31, 2019; Accepted Date: August 23, 2019; Published Date: August 30, 2019

\section{Case Report}

A 6-year-old boy presented in our department of pediatrics because of dysphagia as the primary symptom. Parents told us, that he has to vomit after ingestion of food. These symptoms occur for 1 year. He drinks ice tea and water. Sometimes the patient described stomach pain and watery diarrhea. The family came in 2013 from Togo to Germany. Blood tests done and it revealed anemia with hemoglobin of $5.6 \mathrm{~g} / \mathrm{dl}$, thrombocytes of 479/nl. Heart rate was 116/min, $\mathrm{RR} \mathrm{117/54,} \mathrm{SaO} 2100 \%$, Temperature $36.8^{\circ} \mathrm{C}$. Anemia diagnostic tests reveal Ferritin of $2.3 \mathrm{ng} / \mathrm{ml}$, Reticulocytes $0.7 \%$, and absolute 22 (30-100) with signs of hypoplastic ineffective erythropoiesis. Blood group O rhesus positive, and AKS negative. HIV and CMV were negative. Malaria testing also found negative. Stool analysis was negative with negative calprotectin fecal test. Esophageal diagnostics revealed a short and eccentric post inflammatory stenosis of the esophagus of the upper esophageal sphincter with $4 \mathrm{~mm}$ diameter. ASD II in echocardiography was found. Application of one blood infusion. No hepatosplenomegaly in ultrasonography. Treatment consisted in balloon dilatation of the esophagus for 2 weeks later and iron substitution. A few weeks later the boy was symptom less, the hemoglobin was normal till date.

\section{Discussion}

A severe chronic iron deficiency (sideropenia) is usually accompanied by so-called iron deficiency anemia; anemia. In this context, Plummer-Vinson syndrome, also known as Paterson-Brown-Kelly syndrome, can rarely occur [1-4]. This causes the mucous membrane of the mouth to recede and the tongue and mouth to hurt. A special form is the formation of an esophagus Citation: Stefan Bittmann, Plummer-Vinson Syndrome as an Unusual Cause of Dysphagia and Iron Deficiency Anemia in a 6-year-Old Boy. J Clin Cases Rep 3(2): 56-58. 
http://www.tridhascholars.org | April-2020

membrane, a mucous membrane in the area of the upper esophagus, which causes discomfort when swallowing (dysphagia) [5,6]. The direct cause of Plummer-Vinson syndrome is an iron deficiency. There are several possible causes for this: the most frequent cause (approximately $80 \%$ of cases) is a loss of iron due to chronic bleeding. This can be bleeding from the digestive tract, such as stomach or intestinal ulcers, bleeding gastritis, varicose veins in the esophagus, tumors, hemorrhoids or colonic ulcers [7]. Other possible causes are bleeding from the vagina due to gynecological causes (e.g. intermediate bleeding, bleeding from tumours). Women who have very heavy and long periods are often affected. Bleeding from other organs such as the nose, lungs, bladder or kidneys is also possible, but occurs much less frequently [8]. A severe loss of blood after accidents or surgery can also lead to iron deficiency. Drugs administered to heart attack or stroke patients, for example, which impairs blood coagulation, can also fall into this cause group due to prolonged bleeding. Patients who have to undergo regular blood washing (hemodialysis) or who frequently donate blood can also be affected by iron deficiency anemia. During hemodialysis, the red blood cells are filtered out and injected intravenously back into the body, but many red blood cells are also destroyed during this process [9].

In addition, there are diseases that are accompanied by chronic destruction of the red blood cells and an increased need for iron [10,11]. These include, for example, tumour diseases and inflammations. Further reasons for an iron deficiency can be diseases which reduce or complicate the utilization of iron in the body as well as gastrointestinal or intestinal excision. In some people, the iron requirement is increased by special metabolic situations, including adolescents, pregnant women, breastfeeding women and athletes. People who are treated with vitamin B12 can also suffer from iron deficiency. Another important factor is the lack of iron intake. Infants and toddlers as well as vegetarians are particularly affected, as meat is one of the main sources of iron. The Plummer-Vinson syndrome with mucosal shrinkage of the tongue, oesophagus and pharynx, combined with tongue burning and swallowing disorders, occurs in iron deficiency. In this connection, the so-called sideropenic dysphagia is also reported in cases of pronounced chronic iron deficiency, in which a membrane forms in the upper part of the esophagus, which can lead to difficulty swallowing but is usually not perceived by the patient. The symptoms of iron deficiency or iron deficiency anaemia are very different and can be of varying severity [12,13]. The symptoms can include the formation of grooves and brittleness of the nails, inexplicable hair loss, dry skin, recurring tears in the corners of the mouth (rhagades) and inflammatory changes in the mucous membrane of the mouth (aphthae). The most common are non-specific symptoms such as fatigue, lack of concentration or headaches. General signs of anemia such as fatigue or paleness of the skin and mucous membrane can indicate an iron deficiency, but are very uncertain signs. If there are any indications of a possible iron deficiency, a doctor should always be consulted for clarification. The symptom description and the assessment of the mouth and tongue can already provide good indications of Plummer-Vinson syndrome. If a membrane is not visible when simply looking into the mouth or throat, an oesophagoscopy can be performed if suspicion exists. A small camera is inserted into the esophagus. If there is no other explanation for a swallowing disorder, the so-called esophageal swallowing is used. An X-ray of the esophagus is taken while the patient swallows a contrast medium. In this way, all kinds of pathological changes in the esophagus can be visualized. Swallowing problems can be caused by many different diseases and should therefore be examined carefully. In order to clarify an iron deficiency, the iron storage values (serum ferritin), the form of transport of the iron (transferrin), the blood pigment (hemoglobin) and the iron metabolism are determined in the blood.

\section{References}

1. Novacek G (2006) Plummer-vinson syndrome. Orphanet Journal of Rare Diseases 1(1): 36. 
http://www.tridhascholars.org | April-2020

2. Paterson DR (1919) A clinical type of dysphagia. Proceedings of the Royal Society of Medicine 12(Laryngol_Sect): 235239.

3. Kelly AB (1919) Spasm at the entrance to the oesophagus. The Journal of Laryngology \& Otology 34(8): 285-289.

4. Wynder EL, Hultberg S, Jacobsson F, et al. (1957) Environmental factors in cancer of the upper alimentary tract. A swedish study with special reference to plummer-vinson (Paterson-Kelly) syndrome. Cancer 10(3): 470-487.

5. Ormerod FC (1966) Plummer-Vinson or Paterson-Brown Kelly Priority, Precedence or Prestige?. The Journal of Laryngology \& Otology 80(9): 894-901.

6. Herbella FAM, Matone J, Del Grande JC (2005) Eponyms in esophageal surgery, part 2. Diseases of the Esophagus 18(1): 4-16.

7. Plummer HS (1912) Diffuse dilatation of the esophagus without anatomic stenosis (cardiospasm): a report of ninety-one cases. Journal of the American Medical Association 58(26): 2013-2015.

8. Vinson PP (1919) A case of cardiospasm with dilatation and angulation of the esophagus. Medical Clinics of North America 3: 623-627.

9. Vinson PO (1992) Hysterial Dusphagia. Minesota Medicine 5: 107-108.

10. Nosher JL, Campbell WL, Seaman WB (1975) The clinical significance of cervical esophageal and hypopharyngeal webs. Radiology 117(1): 45-47.

11. Chen TS, Chen PS (1994) Rise and fall of the Plummer-Vinson syndrome. Journal of Gastroenterology and Hepatology 9(6): 654-658.

12. Hoffman RM, Jaffe PE (1995) Plummer-vinson syndrome: A case report and literature review. Archives of Internal Medicine 155(18): 2008-2011.

13. Mansell NJ, Jani P, Bailey CM (1999) Plummer-Vinson syndrome-A rare presentation in a child. The Journal of Laryngology \& Otology 113(5): 475-476. 